\title{
Erratum to: A study of the factors affecting radiation-induced temporomandibular joint changes in post-radiotherapy nasopharyngeal carcinoma patients
}

\author{
Vincent W. C. Wu ${ }^{1}$ Michael T. C. Ying ${ }^{1}$ S. Y. Tam ${ }^{1} \cdot$ Dora L. W. Kwong ${ }^{2}$
}

Published online: 17 October 2016

(C) Springer-Verlag Berlin Heidelberg 2016

Erratum to: J Radiat Oncol (2016) 5:41-46

DOI 10.1007/s13566-015-0215-6

The authors wish to include the below Funding statement.

Compliance with ethical standards

Funding This study was funded by the Hong Kong General Research Fund (GRF No:563412).

The online version of the original article can be found at http:// dx.doi.org/10.1007/s13566-015-0215-6.

Vincent W. C. Wu

htvinwu@polyu.edu.hk

Michael T. C. Ying

michael.ying@polyu.edu.hk

S. Y. Tam

marco.tam@polyu.edu.hk

Dora L. W. Kwong

dlwkwong@hku.hk

1 Department of Health Technology and Informatics, Hong Kong Polytechnic University, Hung Hom, Kowloon, Hong Kong, People's Republic of China

2 Department of Clinical Oncology, University of Hong Kong, Pokfulam, Hong Kong, People's Republic of China 